\title{
Design and experimental testing of the bundled glass column
}

\author{
F. Oikonomopoulou • E. A. M. van den Broek • \\ T. Bristogianni - F. A. Veer - R. Nijsse
}

Received: 15 February 2017 / Accepted: 10 April 2017 / Published online: 2 June 2017

(C) The Author(s) 2017. This article is an open access publication

\begin{abstract}
Glass columns are a promising solution for transparent structural members, capable of transferring the compressive loads in a building while allowing for light and space continuity. Several different types of allglass columns have been explored in the past, nevertheless, they are seldom applied in construction. Reasons include complications in fabrication, lack of adequate strength data but foremost the decreased safety due to the inherent brittleness of glass. This work presents the engineering steps towards the realization of the bundled glass column, from its fabrication method to the experimental testing of series of prototypes in several lengths. Composed of multiple adhesively bonded standardized extruded borosilicate rods, this column can be manufactured relatively easily, achieving a high visual result and sufficient load-bearing capacity. Initially, compressive testing is conducted on series of small-scale prototypes to evaluate the degree of coupling of the rods and the influence of spliced joints along the length of the individual components. Based on the findings, prototypes on a scale relevant to buildings are produced and
\end{abstract}

F. Oikonomopoulou $(\bowtie)$ · E. A. M. van den Broek ·

F. A. Veer · R. Nijsse

Department of Architectural Engineering + Technology,

Faculty of Architecture and the Built Environment, Delft

University of Technology, 2628 BL Delft, The Netherlands

e-mail: f.oikonomopoulou@tudelft.nl

T. Bristogianni $\cdot$ R. Nijsse

Department of Structural Engineering, Faculty of Civil Engineering and Geosciences, Delft University of Technology, $2628 \mathrm{CN}$ Delft, The Netherlands experimentally tested. Finally, prototypes with posttensioning are also tested in compression and evaluated, in an attempt to transform the sudden, brittle mode of failure into ductile. The results demonstrate that the designed bundled column can perform monolithically under loading and has sufficient load-carrying capacity to be considered a structural element. Post-tensioning of the column can contribute to a consistent failure but further development is necessary so that sufficient cooperation between the glass and the steel tendon is achieved.

Keywords Structural glass - Bundled column · Glass columns · Extruded glass profiles · Glass rods . Adhesive joints

\section{Introduction}

1.1 The potential of all glass columns

Large, column-free spaces have long fascinated architects worldwide as they allow for unobstructed views and space and light continuity. Nevertheless, the absence of columns in a building is often linked with expensive and complex structural solutions. Transparent columns, made of glass, could be a promising answer to this conflict between architecture and structural engineering. Revealed only by the play of light and of reflections, free-standing glass columns would disrupt the openness of a space the least while forming structural 
Fig. 1 The five different types of all glass columns as described by Nijsse and ten Brincke (2014)
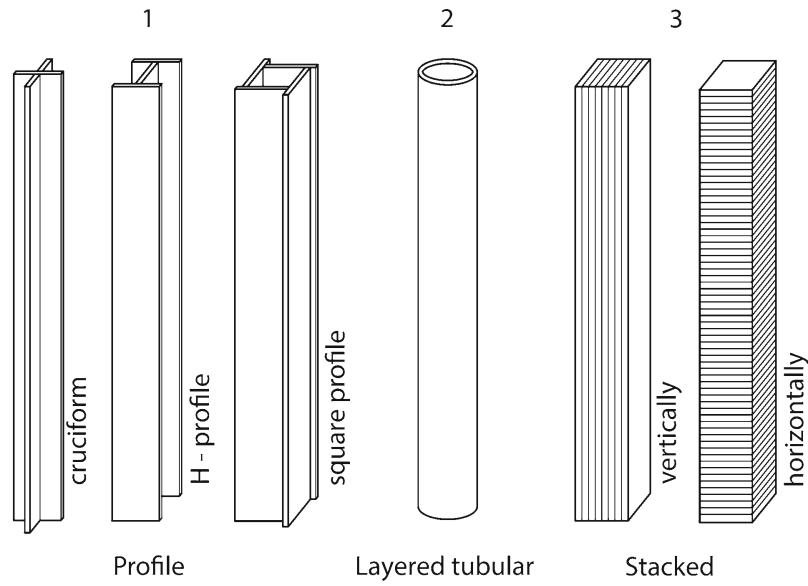

Stacked

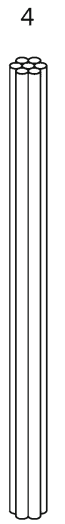

Bundled
5

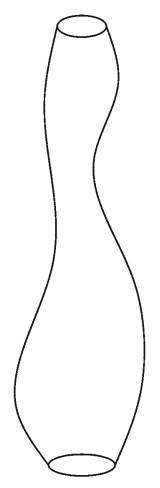

Cast members capable of transferring vertical loads. Indeed, glass's characteristic properties of transparency, durability and of a compressive strength up to $1000 \mathrm{~N} / \mathrm{mm}^{2}$ (Saint Gobain 2016), exceeding that of wood, concrete and even steel (Granta Design Limited 2015), render it the most suitable candidate for realizing diaphanous compressive members. Nevertheless, despite the continuously ascending use of glass in structural components such as beams, portals, shear walls and selfcarrying façades over the last decades, free-standing glass columns are still in a very early stage of development. This can be attributed to the insufficient knowledge regarding their structural behaviour and load carrying capacity under exceptional loading conditions (Kalamar et al. 2016).

\subsection{Previous examples of all glass columns}

To the knowledge of the authors, at present, glass profile columns of a cruciform (X) cross-section are the only type of free-standing glass columns applied in buildings. The first realized example, built in 1994 in St-Germain-en-Laye in France, comprises eight $3.2 \mathrm{~m}$ high cruciform glass columns that support a glass patio. The cruciform profile was selected due to its increased resistance to buckling (Schittich et al. 2007). The same typology of columns was later followed at the Danfoss Headquarters in Denmark, where twelve $5.5 \mathrm{~m}$ high cruciform columns support the reception building (Petersen and Bagger 2009). The inclusion of the columns was only possible after performing 1:1 scale loading tests in which the components demonstrated the ability to carry much higher compressive forces than required. Specifically, the columns applied in the St-Germain-en-Laye office could withstand a force equal to approximately 6 times the calculated maximum load (Nijsse 2003). A series of structural experiments on a full-scale specimen for the Danfoss headquarters proved that even after the column is severely damaged from hard impact under loading, it can still carry an axial load greater than twice the expected maximum force (Petersen and Bagger 2009). Thus, in both examples, the tested columns present a safety factor $>2$. Still, due to the unpredictable and sudden failure of glass, in both cases, the roof is designed with sufficient redundancy to redistribute the forces in case one or more glass columns fail in a complete way (Petersen and Bagger 2009; Nijsse 2003). These two case studies exhibit both the potential and the engineering constraints of all glass columns. Despite having more than adequate load-bearing capacity, the application of glass columns in buildings is linked with increased safety factors compared to standard materials, as well as with the design of alternative load paths to compensate for the lack of a built-in safety system.

Beside these two examples, other configurations of free-standing glass columns have, at present, only been explored within research context and tested in lengths typically restricted to $1.5 \mathrm{~m}$. Exploring the possibilities, (Nijsse and ten Brincke 2014) introduce the following five design concepts of free-standing all-glass columns, illustrated in Fig.1: profile, layered tubular, stacked, cast, and bundled. Table 1 summarizes the geometrical 
Table 1 Geometrical and mechanical properties of characteristic examples of the five types of free-standing columns as stated in literature

\begin{tabular}{|c|c|c|c|c|c|c|c|c|}
\hline $\begin{array}{l}\text { Column } \\
\text { type }\end{array}$ & Configuration & $\begin{array}{l}\text { Cross- } \\
\text { section } \\
(\mathrm{mm})\end{array}$ & $\begin{array}{l}\mathrm{d} \text { of } \\
\text { individual } \\
\text { elements } \\
(\mathrm{mm})\end{array}$ & $\begin{array}{l}\text { Number } \\
\text { of } \\
\text { glass } \\
\text { layers (-) }\end{array}$ & $\mathrm{L}(\mathrm{mm})$ & $\begin{array}{l}\mathrm{F}_{\text {failure }}^{*} \\
\text { in axial } \\
\text { loading } \\
(\mathrm{kN})\end{array}$ & $\begin{array}{l}\sigma_{\text {failure }} \\
(\mathrm{MPa})\end{array}$ & Application \\
\hline X-profile ${ }^{a}$ & $\begin{array}{l}\text { One continuous } \\
\text { laminated panel and } \\
\text { one split in two } \\
\text { bonded with a clear } \\
\text { silicone }\end{array}$ & $449 \times 449$ & 12 & 3 & 5500 & $575^{k}$ & 18.53 & $\begin{array}{c}\text { Danfoss } \\
\text { Office }\end{array}$ \\
\hline$X$-profile ${ }^{b}$ & $\begin{array}{l}\text { One continuous } \\
\text { laminated panel and } \\
\text { one split in two } \\
\text { bonded with a hard } \\
\text { adhesive }\end{array}$ & $400 \times 400$ & $10 / 15 / 10$ & 3 & 3300 & 430 & 16.06 & $\begin{array}{l}\text { St-Germain- } \\
\text { en-Laye }\end{array}$ \\
\hline H-profile ${ }^{c}$ & $\begin{array}{l}\text { Single } 8 \mathrm{~mm} \text { panes } \\
\text { bonded with } \\
\text { Hercuseal polymer }\end{array}$ & $116 \times 100$ & 8 & 1 & 1000 & $212-255$ & $88.4-106.6$ & $\begin{array}{r}\text { Academic } \\
\text { research }\end{array}$ \\
\hline Tubular $^{\mathrm{d}}$ & 1 borosilicate tube & $\varnothing 150$ & 5 & 1 & 4100 & 221 & 97.3 & $\begin{array}{r}\text { Academic } \\
\text { research }\end{array}$ \\
\hline $\begin{array}{l}\text { Layered } \\
\text { tubular }^{\mathrm{e}}\end{array}$ & $\begin{array}{l}2 \text { coaxial borosilicate } \\
\text { glass tubes laminated } \\
\text { together by } \\
\text { low-shrinkage clear } \\
\text { resin }\end{array}$ & $\begin{array}{l}\emptyset_{\text {out }}: 120 \\
\emptyset_{\text {int }}: 95\end{array}$ & 5 & 2 & 1500 & $137-196$ & $40.6-57.9$ & $\begin{array}{r}\text { Academic } \\
\text { research }\end{array}$ \\
\hline Stacked $^{\mathrm{f}}$ & $\begin{array}{l}50 \text { horizontally stacked } \\
\text { float panels bonded } \\
\text { together by SilverTape } \\
8502\end{array}$ & $100 \times 100$ & 12 & $\begin{array}{l}50 \text { hori- } \\
\text { zontally }\end{array}$ & 615 & 525 & 52.5 & $\begin{array}{l}\text { Academic } \\
\text { research }\end{array}$ \\
\hline Cast $^{\mathrm{g}}$ & $\begin{array}{l}10 \text { solid cast glass } \\
\text { blocks bonded } \\
\text { together by } \\
\text { Delo-Photobond } 4468\end{array}$ & $105 \times 105$ & 65 & $\begin{array}{l}10 \text { hori- } \\
\text { zontally }\end{array}$ & 650 & 1412 & 128.0 & $\begin{array}{r}\text { Academic } \\
\text { research }\end{array}$ \\
\hline Bundled $^{\mathrm{h}}$ & $\begin{array}{l}3 \text { hollow tubes bonded } \\
\text { together by a low } \\
\text { modulus structural } \\
\text { silicone }\end{array}$ & $3^{j} \varnothing 24$ & 2.5 & 3 & 1500 & 13.37 & 26.4 & $\begin{array}{l}\text { Academic } \\
\text { research }\end{array}$ \\
\hline Bundled $^{\mathrm{i}}$ & $\begin{array}{l}7 \text { rods of } \varnothing 30 \mathrm{~mm} \\
\text { bonded together by a } \\
\text { clear UV-curing } \\
\text { adhesive }\end{array}$ & Approx. Ø90 & 30 & 7 & 1600 & Not tested & Not tested & $\begin{array}{c}\text { Engineering } \\
\text { concept }\end{array}$ \\
\hline
\end{tabular}

Geometrical and mechanical data provided for ${ }^{a}$ Petersen and Bagger (2009), ${ }^{\mathrm{b}}$ Schittich et al. (2007) ${ }^{\mathrm{c}}$ Ouwerkerk (2011), ${ }^{\mathrm{d}}$ Achenbach and Jung (2003), ${ }^{\mathrm{e}}$ Nieuwenhuijzen et al. (2005), ${ }^{\mathrm{f}, \mathrm{g}}$ Felekou (2016), ${ }^{\mathrm{h}}$ Kamarudin et al. (2016), ${ }^{\mathrm{i}}$ Nijsse (2003)

$\mathrm{j}$ All values provided here concern the force at total failure of specimens tested in compression. Typically testing was performed on one or two specimens, so the derived experimental data cannot be considered statistical

$\mathrm{k}$ The prototype failed at this value after having been subjected to soft and hard impact while loaded to the calculated serviceability limit state axial load of $190 \mathrm{kN}$

and mechanical properties of characteristic samples of the five column types described in this section.

Alternative configurations of profile columns, i.e. $\mathrm{H}, \mathrm{T}, \mathrm{X}$ and square profiles, and their compressive behaviour have been explored experimentally, numer- ically and analytically by Ouwerkerk (2011), Aiello et al. (2011), Campione and Rondello (2014), Overend et al. (2005) and Kalamar et al. (2016). The findings demonstrate that the 3-dimensional geometry of such glass columns results in an increased structural resis- 
tance and stiffness. Most importantly, they manifest that the adhesive connections between the glass elements are of crucial importance to the overall performance. Research and experimental work has been conducted on tubular columns by Achenbach and Jung (2003), Overend et al. (2005), Nieuwenhuijzen et al. (2005) and Veer and Pastunink (1999). Actually, glass tubes have been previously structurally applied but not in the form of columns, with the most characteristic examples being tensegrity structures by the University of Stuttgart (Achenbach et al. 2002) and the glass atrium façade of the Tower Place office building in London (Doenitz et al. 2003). In the latter, the approx. 40 glass tubes that transfer the wind forces to the primary load-bearing system, consist of a core tube laminated to a split tube functioning as an external protecting shell and have a built-in steel cable system. In contrast, the developed column by Nieuwenhuijzen et al. (2005) and Veer and Pastunink (1999) consists of two concentric glass tubes, laminated together by a clear low-shrinkage resin, aiming on utilizing structurally the entire glass composition. This production process, however, involved several practical implications due the adhesive's shrinkage and the dimensional intolerances of the glass tubes. A horizontally stacked, translucent, column made of float glass panels bonded together by an adhesive film has been explored by Van Heugten (2013) and Felekou (2016). Cast and bundled glass columns are until now the least explored options. In theory, cast glass columns could form the ideal solution for transparent load-bearing components. Through casting, monolithic, entirely transparent structural glass members of the desired form and crosssection could be materialized. However, casting glass in such large volumes requires a precise and excessively time-consuming cooling process that renders the manufacturing of storey-high glass columns cost- and timeinefficient. This can be well illustrated by the "Opposites of white" cast sculptures by artist Roni Horn. Each drum-shaped sculpture, $50.8 \mathrm{~cm}$ high by $142 \mathrm{~cm}$ diameter, required 4 months of controlled annealing to prevent the generation of residual stresses (Kroller-Muller Museum 2007). The even larger glass mirror of Hale-1 telescope, following a honeycomb structure and measuring $5 \mathrm{~m}$ in diameter and $0.66 \mathrm{~m}$ in thickness, required 10 months of annealing (Corning Museum of Glass 2011). To overcome the practical limitations involved, the concept of a dry-assembly column consisting of interlocking, vertically stacked, cast glass units of max.

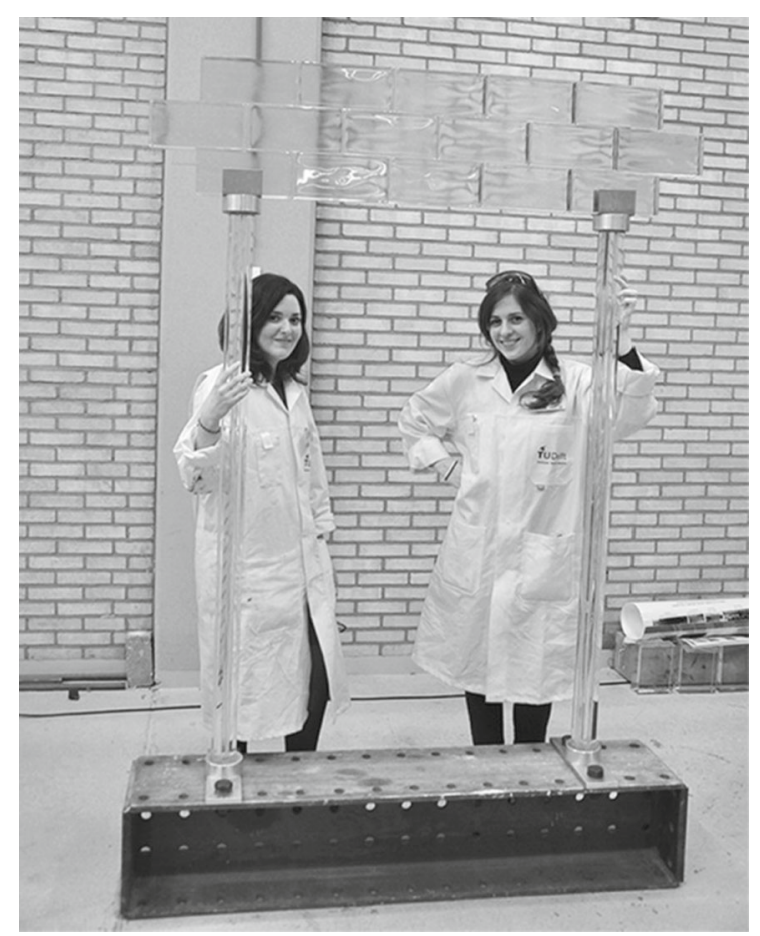

Fig. 2 Realized $1.5 \mathrm{~m}$ long prototypes of the bundled glass column

$10 \mathrm{~kg}$ mass was developed by Akerboom (2016). A similar concept of glass columns consisting of adhesively bonded cast glass bricks has been tested by Oikonomopoulou et al. (2015b) and Felekou (2016).

The bundled column (see Fig. 2) is the fifth type of column, defined by Nijsse (2003) as a safe, all glass column made of a bundle of solid glass bars that are adhesively bonded together. This column concept was first conceived for the ABT Office in Arnhem: 7 glass solid rods of $30 \mathrm{~mm}$ diameter each, in a configuration where the central one is surrounded by the other six, were to be bonded together by a transparent UV-activated glue that would prevent the buckling of each bar individually (Nijsse 2003). Nevertheless, this column was never realized, due to the difficulty in establishing a bonding method and a rod configuration that could ensure consistent results of the desired visual and structural performance. Little experimental data exist so far regarding this type of column. These concern an investigation on the structural performance of a bundle consisting of three hollow glass tubes bonded together by a low modulus structural silicone conducted by Kamarudin et al. (2016). Nevertheless, this research does not address the 

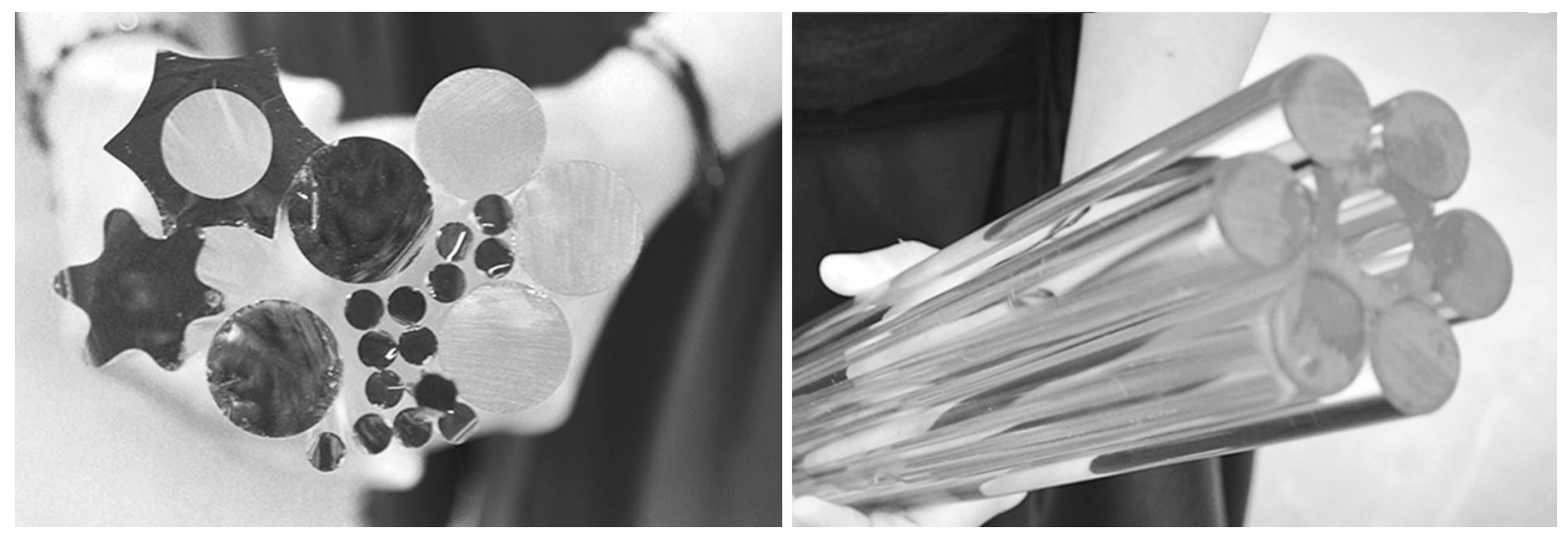

Fig. 3 Left CONTURAX ${ }^{\circledR}$ and DURAN ${ }^{\circledR}$ profiles. Right Concluded configuration of the bundled glass column

attained optical result when bonding the tubes with this method.

\subsection{Realizing the bundled glass column}

This paper presents the research and experimental testing and discusses the feasibility of the fifth type of glass columns, the bundled. This alternative has not been explored in depth until now even though it presents great prospects in terms of fabrication, visual result and structural performance. In this work, a production method for constructing bundled glass columns on a scale relevant to buildings is first described, analysing the practical limitations and proposed solutions. Following, series of prototypes in different scales are made and tested in compression and the results are discussed in terms of structural performance. Lastly, in an attempt to introduce a more gradual and visible buckling failure the concept of post-tensioning is introduced to fullscale specimens and experimentally evaluated. Based on the findings, suggestions are made for further engineering the bundled column.

\section{Design concept and production considerations}

The concept of the bundled column is simple. Multiple glass bars are bonded together by a colourless adhesive, forming a composite yet integral cross-section. In terms of visual performance, the bundled glass column is transparent, yet not invisible. The curved geometry of the rods generates playful distortions and light reflections, subtly revealing the existence of the column (Oikonomopoulou et al. 2016). The column's load-carrying capacity is enhanced by the symmetrical cross-section of both the rods and the composite shape. Solid rods of a circular cross-section from the DURAN@ series by Schott are selected due to their inherent resistance in buckling and torsion. These are standardized, extruded borosilicate glass rod profiles, $1500 \mathrm{~mm}$ in length, with diameters ranging from $3( \pm 0.14)$ to $30( \pm 0.80) \mathrm{mm}$ (SCHOTT 2012). To create a symmetrical bundle, a configuration comprising seven extruded profiles, a central one surrounded by six external ones, is further examined. Initially, different fabrication methods comprising seven rods of identical circular cross-section were explored. Such a rod arrangement proved incapable of guarantying a consistent visual and structural result, due to its inability to account for the standard diameter deviation of the rods and the visible distortions caused by the adhesive lines (Oikonomopoulou et al. 2016). A new configuration was proposed, consisting of a central hollow star-shaped CONTURAX ${ }^{\circledR}$ profile and six external DURAN ${ }^{\circledR}$ rods with a diameter corresponding to the convex of the flutes of the central star profile. The CONTURAX $^{\circledR}$ profile is commercially only available with a $17( \pm 2.00) \mathrm{mm}$ inner and $30( \pm 2.00) \mathrm{mm}$ external diameter (SCHOTT AG 2013). To match the central profile's curvature, the six external DURAN ${ }^{\circledR}$ rods have a diameter of $22( \pm 0.45) \mathrm{mm}$ (see Fig. 3). The construction of several prototypes proved that the matching curvature between the surface of the rods and the flutes of the central profile allows for consistent bonding stripes 
of a high visual result, despite the tolerances in the size of the individual components (Oikonomopoulou et al. 2016).

The adhesive connection between adjacent glass components plays a key role in the overall structural performance of glass columns (Kalamar et al. 2016). Thus, the degree of mechanical collaboration between the rods is highly dependent on the applied adhesive. The higher the bonding strength, the more the adjacent elements couple, preventing individual buckling. Delo Photobond 4468, a one-component, clear, UV-curing acrylate, was selected for bonding the elements together due to its colourless nature, similar refraction index to glass, fast application and very good mechanical properties (Delo Industrial Adhesives 2014). The specific adhesive was also applied in the construction of the Crystal Houses façade in Amsterdam (Oikonomopoulou et al. 2017). 4-point bending experiments on glass beams consisting of adhesively bonded solid glass bricks by Oikonomopoulou et al. (2015a) demonstrated the monolithic behaviour of the glass-adhesive assembly under loading.

\section{Fabrication of the prototypes: materials and methods}

\subsection{Overview of specimens}

Based on the proposed manufacturing method, series of specimens in different scales are made and experimentally tested in compression. Figure 4 shows an illustration of the series of prototypes and Table 2 summarizes their geometrical characteristics and boundary conditions.

Compression testing is initially carried out on series of small prototypes $\left[\mathrm{A}_{1}\right.$ and $\mathrm{A}_{2}$ ] to evaluate the degree of coupling between the rods when bonded with the selected adhesive, as well as the influence of spliced connections along the length of the rods. For this purpose, the results of these series will be discussed separately in Sect. 4, since they are used as the basis for the fabrication of longer specimens. Following, series of specimens in a scale relevant to buildings $\left[\mathrm{B}_{1}\right.$ and $\mathrm{B}_{2}$ ] are tested in compression until failure and the results are discussed in terms of load-carrying capacity and failure behaviour. Finally, a series of prototypes with an introduced axial post-tensioned steel tendon $\left[\mathrm{C}_{1}\right]$ is built and tested in compression with the

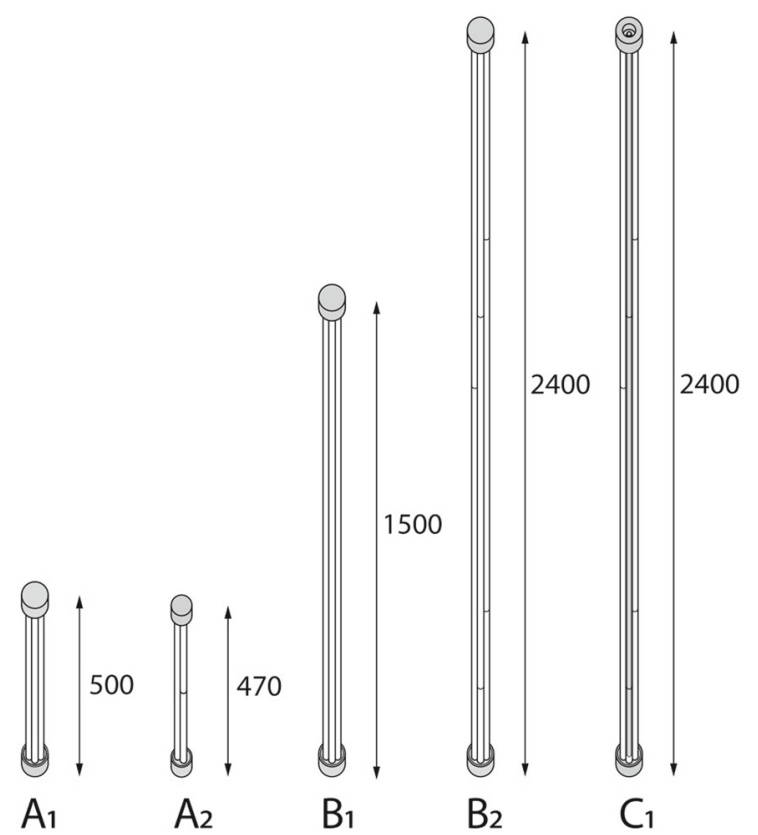

Fig. 4 Illustration of all specimen series tested in compression

aim of attaining a more gradual and visible buckling failure.

\subsection{Production method of the glass bundle}

Based on the findings of Sect. 2, each specimen consists of a central hollow star-shaped CONTURAX ${ }^{\circledR}$ borosilicate glass profile with $17( \pm 2.00) \mathrm{mm}$ inner and $30( \pm 2.00) \mathrm{mm}$ external diameter adhesively bonded to 6 borosilicate DURAX® rods of $\varnothing 22( \pm 0.45) \mathrm{mm}$, which form the external bundle (see Fig. 5).

The rods are bonded one by one in a horizontal position to the flutes of the central profile along their length, in a strip approx. $8 \mathrm{~mm}$ wide, by Delo Photobond 4468 adhesive. The latter is fully cured during a minimum of $40 \mathrm{~s}$ using $60 \mathrm{~mW} / \mathrm{cm}^{2}$ UVA intensity (Delo Industrial Adhesives 2014). An illustration of the bonding method can be seen in Fig. 6.

All glass profiles used are properly annealed in Schott's premises. Each profile is carefully cut to size using a diamond blade saw and its ends are manually ground. Once the profiles are bonded together and the bundle is formed, the top and bottom surfaces are manually ground again carefully to remove any protrusions due to misalignment or difference in length of the individual rods and to obtain a flat surface perpendicular to the axis. 
Table 2 Overview of the specimens' characteristics

\begin{tabular}{|c|c|c|c|c|c|c|c|}
\hline $\begin{array}{l}\text { Specimen } \\
\text { series }\end{array}$ & $\begin{array}{l}\text { Glass bundle } \\
\text { composition }\end{array}$ & $\begin{array}{l}\text { Least second } \\
\text { moment of area } \\
\mathrm{I}\left(\mathrm{mm}^{4}\right)\end{array}$ & $\begin{array}{l}\text { Length } \\
(\mathrm{mm})\end{array}$ & $\begin{array}{l}\text { End } \\
\text { conditions }\end{array}$ & $\begin{array}{l}\text { Spliced } \\
\text { lamination }\end{array}$ & Post-tensioning & $\begin{array}{l}\text { No. of } \\
\text { specimens }\end{array}$ \\
\hline $\mathrm{A}_{1}$ & $\begin{array}{r}6 \times \varnothing 22 \text { rods }+ \\
1 \times \text { star-shape }\end{array}$ & 643170 & 500 & Clamped & No & No & 3 \\
\hline $\mathrm{A}_{2}$ & $3 \times \varnothing 22$ rods & 126464 & 470 & Clamped & Yes & No & 12 \\
\hline $\mathrm{B}_{1}$ & $\begin{array}{r}6 \times \varnothing 22 \text { rods }+ \\
1 \times \text { star-shape }\end{array}$ & 643170 & 1500 & Clamped & No & No & 3 \\
\hline $\mathrm{B}_{2}$ & $\begin{array}{r}6 \times \emptyset 22 \text { rods }+ \\
1 \times \text { star-shape }\end{array}$ & 643170 & 2400 & Pinned & Yes & No & 3 \\
\hline $\mathrm{C}_{1}$ & $\begin{array}{r}6 \times \emptyset 22 \text { rods }+ \\
1 \times \text { star-shape }\end{array}$ & 643170 & 2400 & Pinned & Yes & Yes & 3 \\
\hline
\end{tabular}

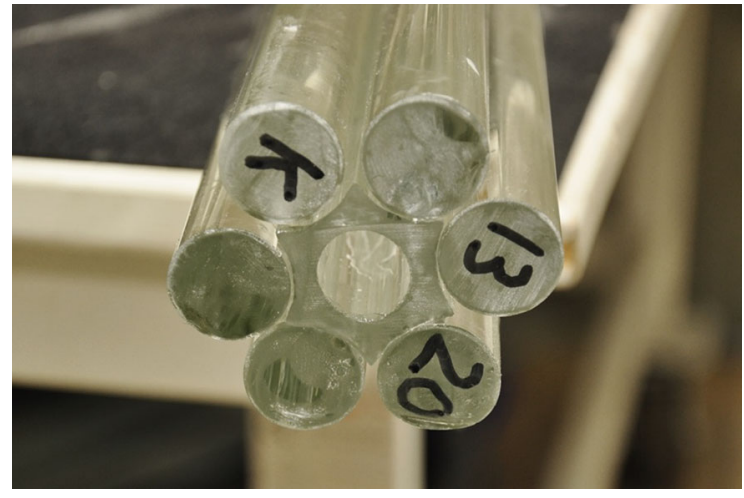

Fig. 5 The bundled column cross-section

\subsection{End connections of specimens}

\subsubsection{Clamped connections of specimen series $\mathrm{A}_{1}, \mathrm{~A}_{2}$ and $\mathrm{B}_{1}$}

Specimens $\mathrm{A}_{1}, \mathrm{~A}_{2}$ and $\mathrm{B}_{1}$ are tested while establishing clamped connections in the testing machine, as such:
At both ends of the bonded glass bundle two milled aluminium caps are mounted to form the top and bottom bases (see Fig. 7). The caps, besides stabilizing the bundle, prevent direct contact between the glass and the steel surface of the testing machine. Prior to mounting, a soft, $1 \mathrm{~mm}$ thick sheet of lead is placed inside each aluminium head (see Fig. 7). This yielding interlayer allows for the even distribution of the applied compression load, preventing peak stress concentrations due to possible unevenness in the glass' contact surface. The connection between the aluminium cap, coated with the inlayed lead, and the glass bundle is realized by a clear adhesive. In specific, once the column is aligned to be in the centre of the aluminium head, a two-component clear polyurethane is carefully mixed and poured in between the glass and aluminium at the ground base to create a rigid head. Crystal Clear ${ }^{\circledR}$ 200 resin is chosen due to its water and UV- resistance and negligible shrinkage (SMOOTH-ON 2016). This resin is left to cure for a minimum of $16 \mathrm{~h}$. Then the column is flipped and the other side is treated the same way.

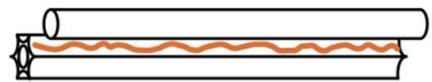

Fig. 6 Schematic illustration of the bonding method applied to the glass bundle. From left to right The rods are individually bonded to the flutes of the central profile in a horizontal posi-
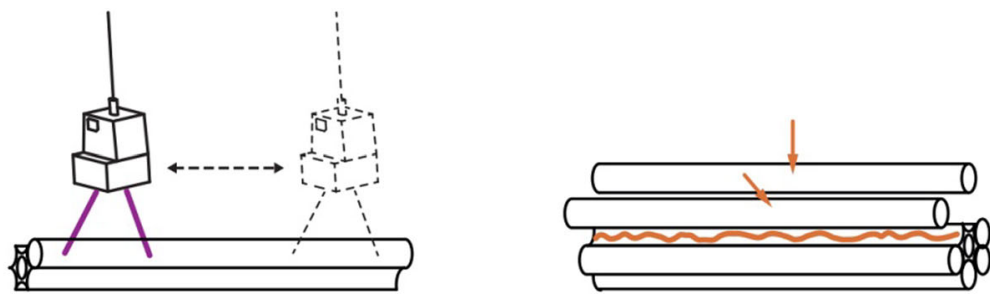

tion and cured by a UV-lamp travelling back and forth along its length. The process is repeated for each rod until the bundle is complete 


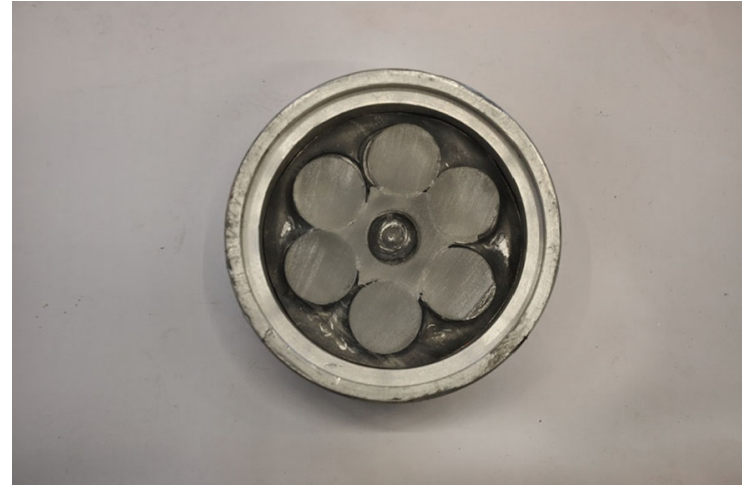

Fig. 7 The aluminium cap with the inlayed lead sheet and a section of the glass bundle

\subsubsection{Pinned connections of specimen series $B_{2}$}

In specimen series $B_{2}$ the same aluminium cap connections are applied, yet an addition is made to the detail so that the columns are tested in a pinned configuration. Specifically, a steel cap with a milled convex and a corresponding half-sphere steel component is placed under the base aluminium cap (see Fig. 8). For the top connection the same detail is applied above the top aluminium cap, by an identical steel cap welded to the steel surface of the testing machine (see Fig. 8). Prior to testing, the complete specimen is stabilized by restraining the height of the column through carefully adjusting the machine's top pressing plate so that contact is made. The force introduced before the experiment starts is negligible.

\subsubsection{Pinned connections of specimen series $C_{1}$ and application of the post-tensioning}

The production process for the $\mathrm{C}_{1}$, post-tensioned variant of $2400 \mathrm{~mm}$ length, is identical to the $\mathrm{B}_{2}$ series of prototypes with the exception of the post-tensioning tendon and the use of steel top and bottom caps. The hollow core of the central star-shaped CONTURAX ${ }^{\circledR}$ borosilicate glass profile, of $17( \pm 2.00) \mathrm{mm}$ diameter, is used to accommodate the post-tensioning tendon. To account for the $\pm 2.00 \mathrm{~mm}$ production tolerance in the inner diameter of this profile, a standardized M12 threaded rod is used as tendon with PVC tubing, of $16 \mathrm{~mm}$ outer and $13.6 \mathrm{~mm}$ inner diameter, around it, to prevent direct contact between the steel and the glass (see Fig. 9). Due to the inevitable production tolerances of the CONTURAX® profile, the PVC-coated tendon
Fig. 8 Top (left) and bottom (right) pinned connections of the experimental set-up of the $\mathrm{B}_{2}$ specimen series

Fig. 9 Left Position of the steel tendon and PVC tube at the post-tensioned specimens. Right The steel cap detail
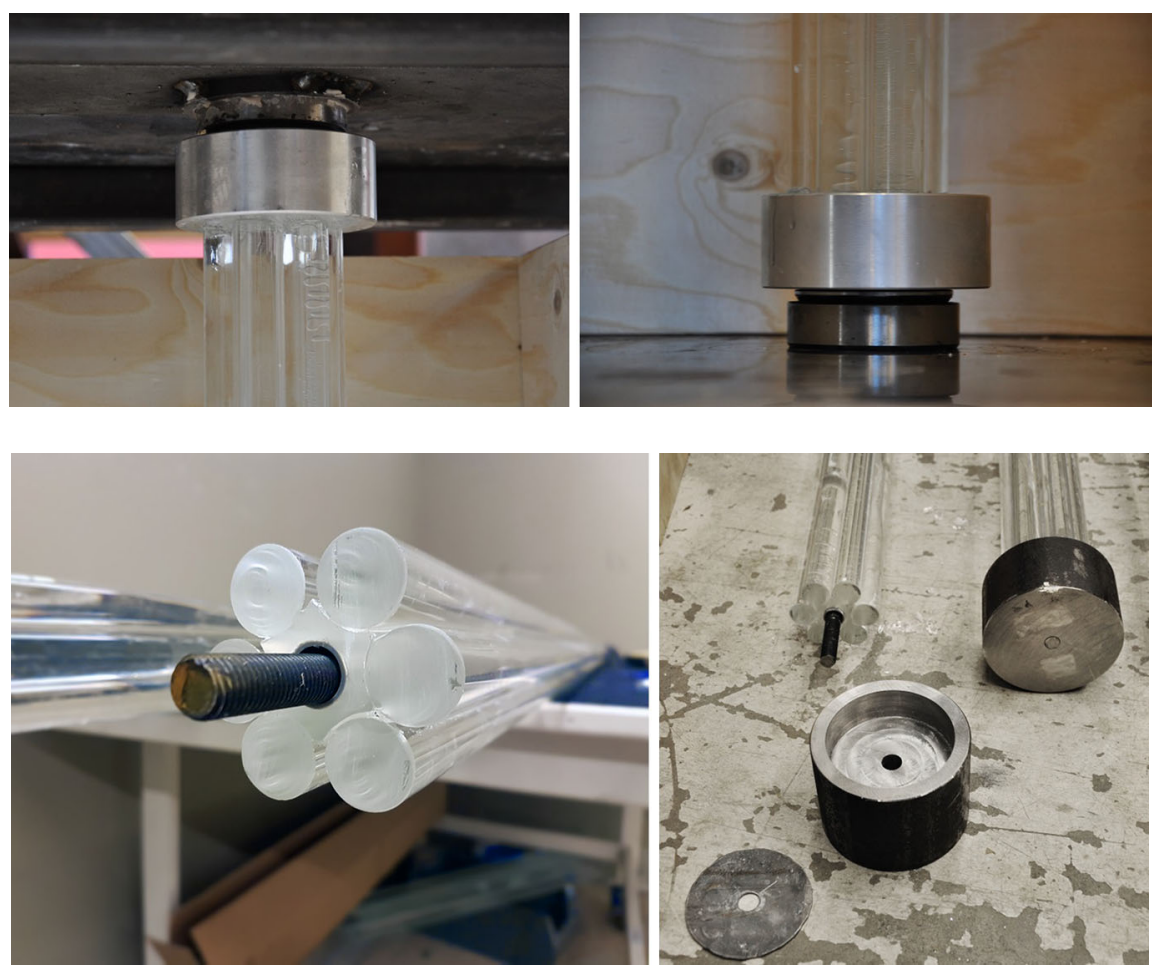

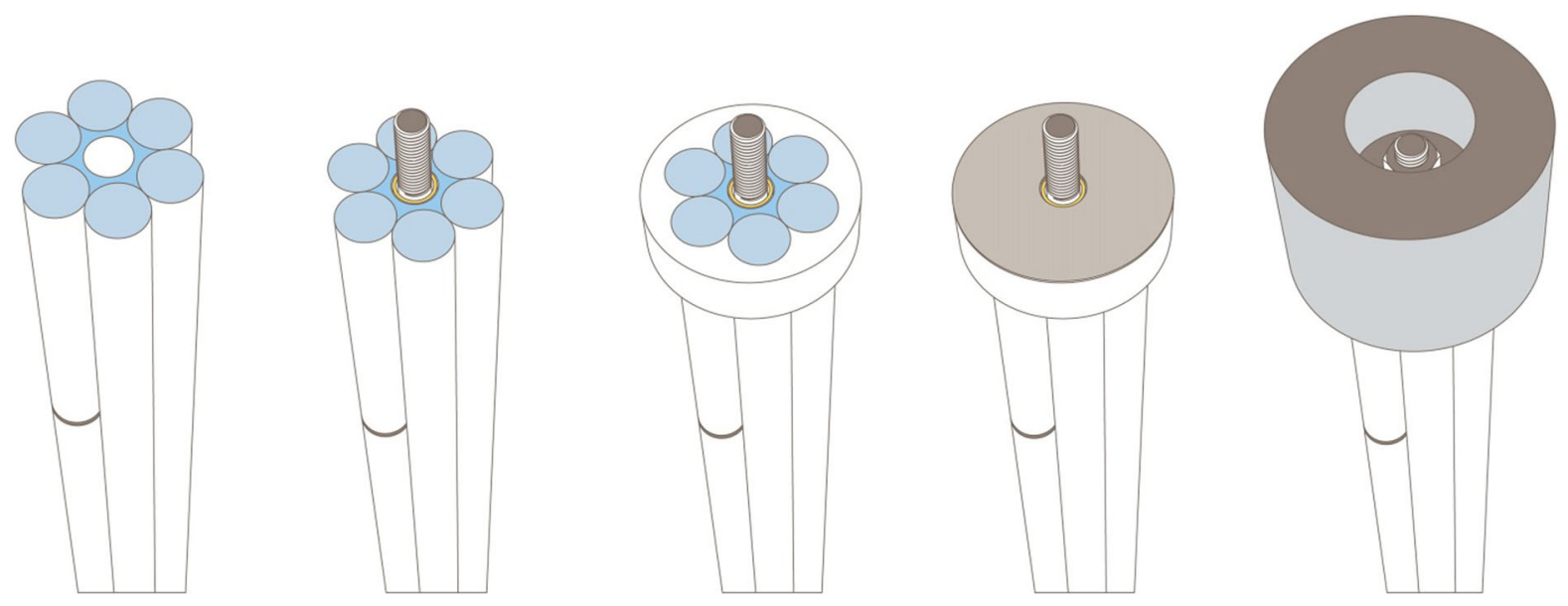

Fig. 10 Illustration of the post-tensioned glass column head detail

is not in direct contact with the glass, but as close to glass as possible using stock materials.

Pre-stress applied to a tendon is dependent on the type of steel. Although material properties vary, an approximate estimate of proof strength is $85-90 \%$ of its yield strength (Shigley and Mitchell 1993). Using 8.8 bolt quality steel the torque value that can be safely applied is $80( \pm 10) \mathrm{Nm}$, which translates to roughly $35 \mathrm{kN}$ of axial force. ${ }^{1}$ The post-tensioning is applied using a Stahlwille 730/10 torque wrench with corresponding square drive which allows for a maximum torque application of $100 \mathrm{Nm}$.

In contrast to all previous specimens, the posttensioned columns heads are made of the same 8.8 quality steel as the post-tensioning tendon, nut and washer (see Fig. 9) for better cooperation of the components. The bottom steel cap has an axial hole with a female M12 thread in which the post-tensioned tendon can be fixed. The top steel cap has a $13 \mathrm{~mm}$ hole to allow free passage of the tendon, which is tightened with a M12 washer and nut using the torque wrench (see Fig. 10). In these steel heads a $1 \mathrm{~mm}$ thick layer of lead is again used as intermediary to prevent direct contact between the

\footnotetext{
${ }^{1}$ A M12 of 8.8 quality steel has a tensile strength of approximately $62.8 \mathrm{kN}$. To be within a safe margin, the pre-stress applied to the tendon was decided to be approx. 55\% of this strength. Quality 8.8 bolt steel was chosen for this research as the use of lower quality steel, and consequently a lower amount of applied pre-stress, would make the monitoring of the expected effect more difficult. The use of 8.8 steel results as well into an applied pre-stress lower than the critical buckling force. Thus, in case of accidental damage of the column, the latter would not buckle under the pre-stress applied alone.
}

glass column and the steel heads. The same pinned connection details between steel caps and testing machine are applied, as described in the $\mathrm{B}_{2}$ specimens.

\section{Testing of $A_{1}$ and $A_{2}$ series: initial evaluation of the coupling degree between the rods and the influence of spliced connections}

Prior to the production of longer specimens it was essential to evaluate the degree of coupling between the rods when bonded with the selected adhesive, as well as the influence of spliced connections necessary for the fabrication of prototypes exceeding the standardized rod length of $1500 \mathrm{~mm}$. Therefore, two series of small scale prototypes, namely $\mathrm{A}_{1}$ and $\mathrm{A}_{2}$, were made and tested under compression to evaluate each of the two parameters respectively. These tests and their results are presented below.

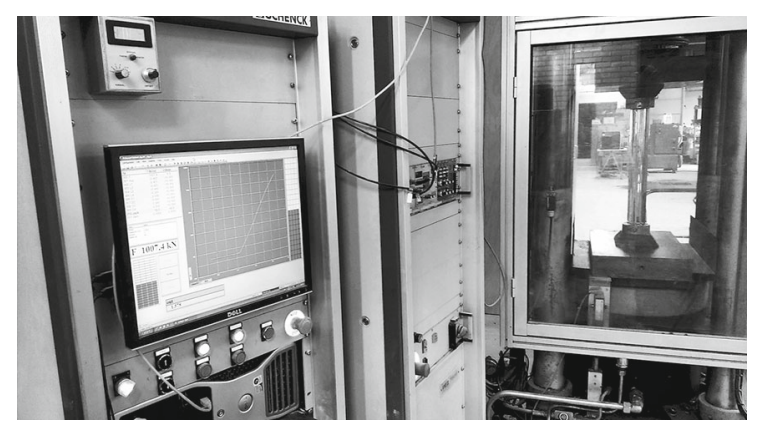

Fig. 11 Experimental set-up of $A_{1}$ specimens 
Table 3 Dimensions and failure stress values of the A1 specimen series

\begin{tabular}{llllll}
\hline Specimen & Length $(\mathrm{mm})$ & Composition of the bundle & Surface area $\left(\mathrm{mm}^{2}\right)$ & Failure load $(\mathrm{kN})$ & $\begin{array}{l}\text { Nominal compressive } \\
\text { failure stress }(\mathrm{MPa})\end{array}$ \\
\hline 1 & 500 & $6 \times \varnothing 20$ rods $+1 \times$ star-shape & 2156 & 1009.9 & 468 \\
2 & 500 & $6 \times \varnothing 22$ rods $+1 \times$ star-shape & 2552 & 1320.2 & 517 \\
3 & 500 & $6 \times \varnothing 22$ rods $+1 \times$ star-shape & 2552 & 1320.0 & 517 \\
\hline
\end{tabular}

\subsection{Testing of $A_{1}$ series: evaluation of the degree of coupling of the rods}

To examine the degree of coupling between the individual rods, compression tests were conducted at the $\mathrm{A}_{1}$ series of prototypes of $500 \mathrm{~mm}$ length. The experimental set-up can be seen in Fig. 11. Table 3 summarizes the dimensions, failure load and corresponding nominal compressive stress of the three tested specimens.

All specimens failed in a sudden and complete way at a consistent compressive stress of approximately $500 \mathrm{MPa}$. The high failure stress indicates that, owing to the lead sheet insert, edge flaws and unevenness on the length of the individual glass rods have a minor influence, if any at all, to the total load-carrying capacity. Most importantly, the consistency and magnitude of the failure stress values suggest that either the compressive strength of glass ${ }^{2}$ or the compressive shear strength of the adhesive have been reached. In either case, it is safe to assume that the high shear stiffness of the selected adhesive enables the bundle to behave as a single monolithic unit under a compressive force less than $1000 \mathrm{kN}$.

\subsection{Testing of $A_{2}$ series: evaluation of the influence of spliced connections}

According to SCHOTT AG (2017), the maximum manufacturing length in extruded profiles is $10 \mathrm{~m}$, sufficient for realizing even three-storey high columns. Nevertheless, in practice, Schott's extruded profiles are standardized up to $1500 \mathrm{~mm}$ length. Communication with

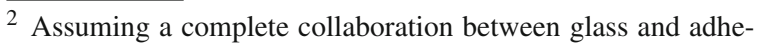
sive and clamped connections, based on Euler's formula for buckling the theoretical critical buckling force would be approx. $3800 \mathrm{kN}$. This in turn, corresponds to a compressive stress of approx. $1500 \mathrm{MPa}$, a value higher than the stated compressive strength of glass. Hence, it is assumed that the specimens fail under compression.
}

the manufacturer suggested that longer profiles can be produced only for orders exceeding $500 \mathrm{U}$. Due to cost restrictions such an order was not possible. Hence, to produce specimens applicable in a building scale, a configuration similar to the splice-lamination principle was applied. Specifically, the column is segmented so that the connection points spiral up along its height. In this way, the generation of weaker zones is minimized. To optimize the material use of the standardized $1500 \mathrm{~mm}$ rods, every split point of the spiral, splice-lamination is in $250 \mathrm{~mm}$ absolute height distance from the split point of the adjacent rod. An illustration of this scheme is given in Fig. 12.

The influence of three alternative connection types, each $2 \mathrm{~mm}$ thick, to the column's carrying capacity is further evaluated by the experimental testing of the $\mathrm{A}_{2}$ series of prototypes: an empty gap, a gap filled with Delo Photobond 4494 adhesive and an aluminium ring connection. Delo Photobond 4494 is opted due to its compatibility with Delo Photobond 4468, its good mechanical properties (Delo Industrial Adhesives 2016), medium viscosity and ability to form a $2 \mathrm{~mm}$ thick joint. ${ }^{3}$ Aluminium (bonded with Delo Photobond 4468 to the glass surfaces) is chosen due to its comparable to glass, yet slightly lower, Young's Modulus. A series of three $470 \mathrm{~mm}$ high specimens consisting each of 3 adhesively bonded rods of $\varnothing 22( \pm 0.45) \mathrm{mm}$, where one is interrupted in the middle (see Fig. 13) are made for each connection type and tested until failure in a displacement controlled hydraulic compression machine with a $1 \mathrm{~mm} / \mathrm{min}$ rate of loading. The results of each series, summarized in Fig. 14, are compared

\footnotetext{
3 Oikonomopoulou et al. (2017) states that Delo Photobond 4468 reaches its optimum bond strength when applied in a layer $0.2-$ $0.3 \mathrm{~mm}$ thick. In this case, the $2 \mathrm{~mm}$ thickness of the joint requires a thicker adhesive that can still guarantee a good collaboration between the glass components. Delo Photobond 4494, of the same adhesive family, achieves a relatively lower strength bond between glass components, yet can be applied in the required thickness.
} 
Fig. 12 Splice-lamination scheme of specimens $\mathrm{B}_{2}$ and $\mathrm{C}_{1}$
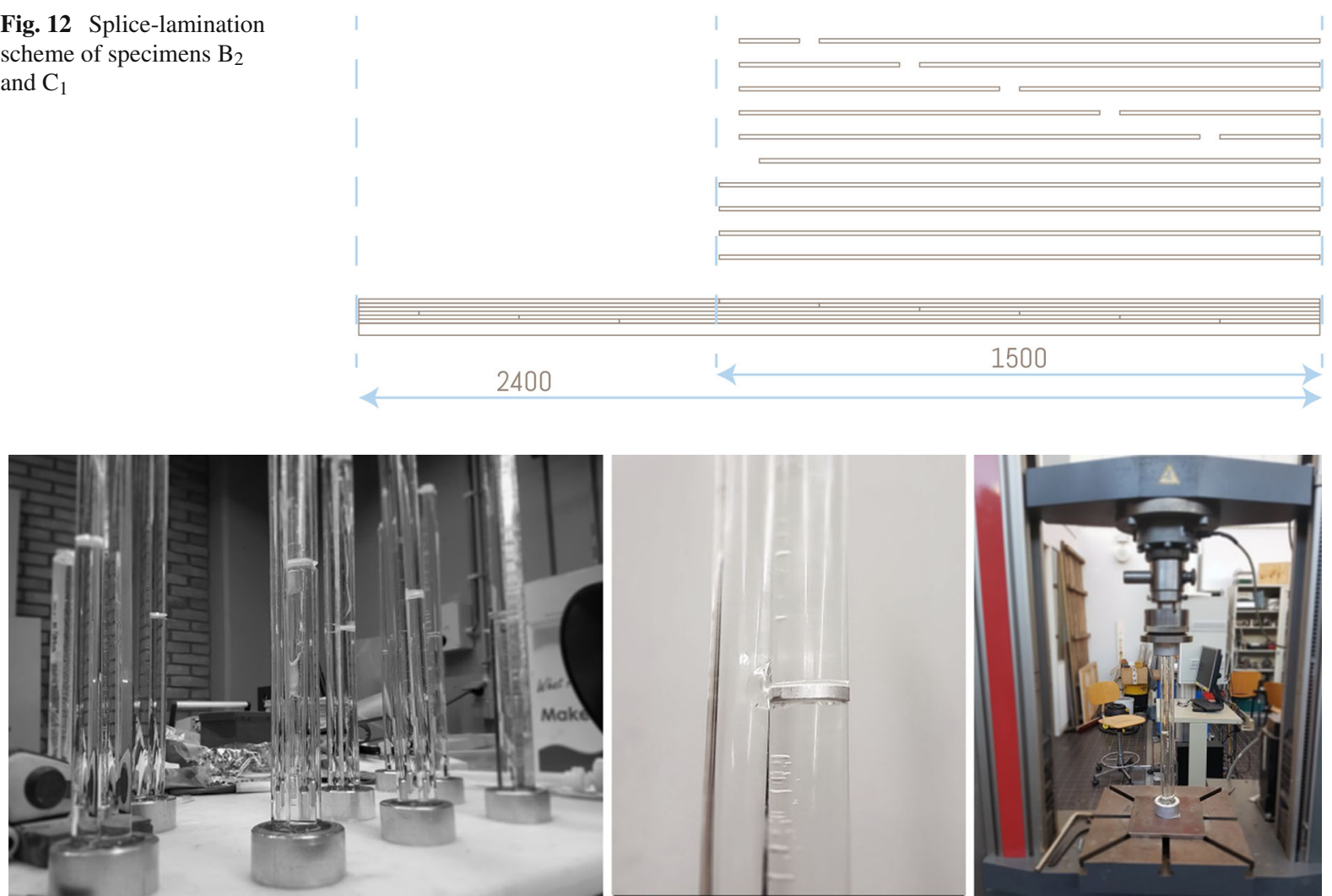

Fig. 13 Left Specimens for testing. Center detail of the aluminium disc spliced joint. Right Experimental set-up

to the structural performance of a series of identical specimens comprising monolithic, undisrupted rods.

Specimens failed under forces ranging between $95 \mathrm{kN}$ and $277 \mathrm{kN} .{ }^{4}$ Figure 14 clearly indicates that

\footnotetext{
${ }^{4}$ It should be noted here that the failure stress values (approx. $240 \mathrm{MPa}$ ) of the monolithic variant of the $\mathrm{A}_{2}$ series are significantly lower than the ones obtained from the $A_{1}$ specimen series $(468-517 \mathrm{MPa})$. The authors attribute the above difference in values to the non-optimal application of the adhesive in the $\mathrm{A}_{2}$ specimen series. In the $A_{1}$ series, with to the central star profile present, the adhesive can be easily applied along the whole length of the rods in a consistent layer of circa $0.2-0.3 \mathrm{~mm}$ thickness. Oikonomopoulou et al. (2017) states this thickness as providing the optimum bonding strength of the specific adhesive and argues on why a thicker adhesive joint has a negative effect in the structural performance of the glass-adhesive assembly. In the case of the $A_{2}$ specimens, the geometry of the triple bundle without core results in a significantly thicker and inconsistent adhesive layer at its centre. Accordingly, the increased thickness of the adhesive joint results to decreased bond strength and subsequently to a reduced structural performance of the bundle. This single example demonstrates the significance of the proper design and bonding of the components in order to achieve the desired degree of coupling between the individual elements.
}

the specimens with aluminium disc connections are mechanically the closest to the monolithic variant. From the results it can be derived that aluminium performs at approx. $85 \%$ of the full glass sample. In comparison, the adhesive connection performs at roughly $55 \%$ of the benchmark and the empty gap at $35 \%$. Therefore, in this work, for the fabrication of the $2400 \mathrm{~mm}$ long specimens of the $B_{2}$ and $C_{1}$ series aluminium disks are selected for the split connectors between rods (see Fig. 15).

\section{Compression testing on series $B_{1}, B_{2}$ and $C_{1}$}

The structural performance and failure behaviour of the designed bundled column is evaluated through compression tests until complete failure on a series of clamped specimens of $1500 \mathrm{~mm}$ length $\left[\mathrm{B}_{1}\right]$, pinned specimens of $2400 \mathrm{~mm}$ length $\left[\mathrm{B}_{2}\right]$, and pinned posttensioned specimens of $2400 \mathrm{~mm}$ length $\left[\mathrm{C}_{1}\right]$, using a force-controlled hydraulic compression machine (see 
Fig. 14 Carrying capacity of the $\mathrm{A}_{2}$ specimens with alternative connection types: Empty: 1-3,

Adhesive connection: 4-6, Aluminium connection: 7-9, Monolithic rods: $10-12$

Fig. 15 Right Prototypes of the $\mathrm{B}_{2}$ series using the spliced lamination principle in a spiral configuration, seen on the left
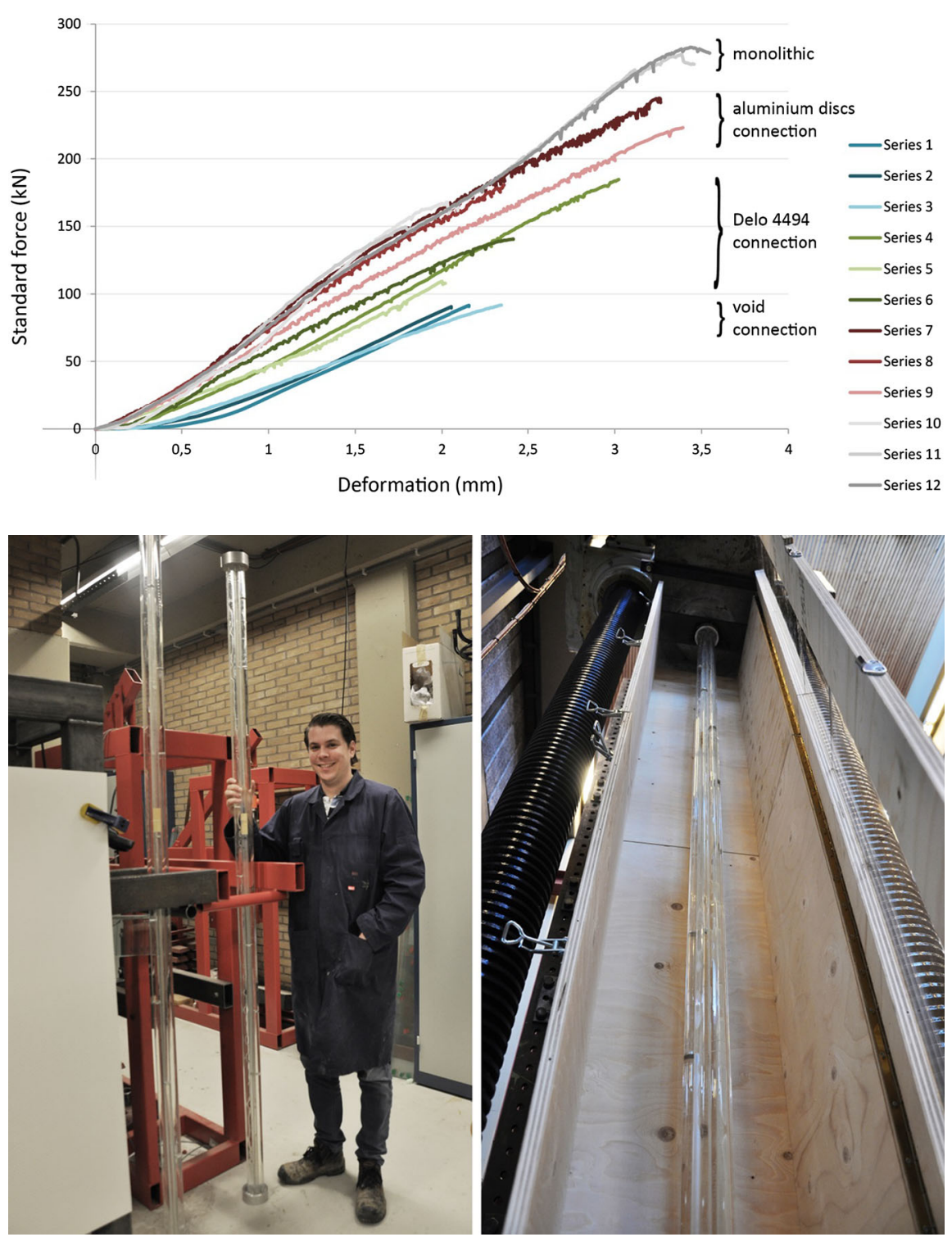

Fig. 16). There are three identical specimens for each series. The production of the prototypes has been thoroughly described in Sect. 3.

In the case of the $\mathrm{B}_{1}$ specimens, the available standardized $1500 \mathrm{~mm}$ length of the rods allows for a continuous bundle, sparing the necessity of splicing rods. The top and bottom aluminium caps are in direct contact with the steel surface of the testing machine and thus are expected to behave as clamped connections.

The longer specimens of the $\mathrm{B}_{2}$ and $\mathrm{C}_{1}$ series consist of the same rod configuration as the $\mathrm{B}_{1}$ prototypes, yet they follow a spiral, splice-lamination scheme. Based on the findings of the testing described in Sect. 4.2,
$2 \mathrm{~mm}$ thick aluminium disks bonded with Delo Photobond 4468 to the rods form the split connectors.

The $\mathrm{B}_{2}$ and $\mathrm{C}_{1}$ specimens are tested in compression in a set-up with pinned top and bottom supports. For safety reasons, during testing, all specimens are surrounded by a wooden safety cage with a polycarbonate window.

\section{Discussion of the experimental results}

The results of the compression tests in $\mathrm{B}_{1}, \mathrm{~B}_{2}$ and $\mathrm{C}_{1}$ specimen series are summarized in Table 4. 
Fig. 16 Left Experimental set-up for the $\mathrm{B}_{1}$ series (clamped). Right

Experimental set-up for the $\mathrm{B}_{2}$ series (pinned)
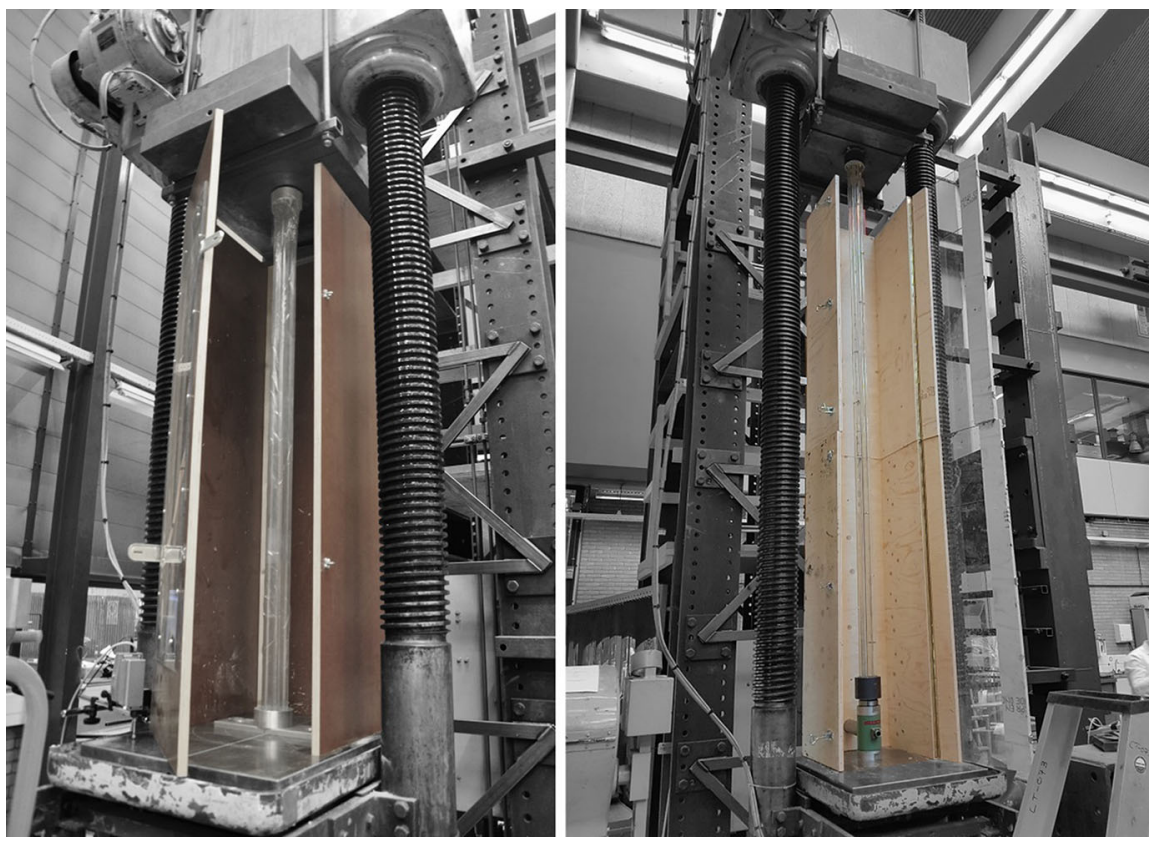

Table 4 Dimensions and strength values of $\mathrm{B}_{1}, \mathrm{~B}_{2}$ and $\mathrm{C}_{1}$ series of specimens

\begin{tabular}{|c|c|c|c|c|c|c|c|c|c|}
\hline Series & Spec. no. & $\begin{array}{l}\text { Length } \\
(\mathrm{mm})\end{array}$ & $\begin{array}{l}\text { end } \\
\text { connections }\end{array}$ & Post-tension & $\begin{array}{l}\text { Approx. load where first } \\
\text { crack was observed }(\mathrm{kN})\end{array}$ & $\mathrm{F}_{\max }(\mathrm{kN})$ & $\mathrm{F}_{\mathrm{cr}}(\mathrm{kN})$ & $\sigma \max .(\mathrm{MPa})$ & $\lambda$ \\
\hline \multirow[t]{3}{*}{$\mathrm{B}_{1}$} & 1 & 1500 & Clamped & No & N.R. & 331.0 & 722.2 & 129.70 & 47 \\
\hline & 2 & & & & 260 & 389.4 & & 152.57 & \\
\hline & 3 & & & & 120 & 508.8 & & 199.36 & \\
\hline \multirow[t]{3}{*}{$\mathrm{B}_{2}$} & 1 & 2400 & Pinned & No & 45 & 63.0 & 70.5 & 24.70 & 151 \\
\hline & 2 & & & & N.R. & 75.0 & & 29.40 & \\
\hline & 3 & & & & 70 & 90.0 & & 35.30 & \\
\hline \multirow[t]{3}{*}{$\mathrm{C}_{1}$} & 1 & 2400 & Pinned & Yes & N.R. & 69.0 & 70.5 & 27.00 & 151 \\
\hline & 2 & & & & N.R. & 64.4 & & 25.20 & \\
\hline & 3 & & & & N.R. & 62.7 & & 24.60 & \\
\hline
\end{tabular}

The maximum nominal compressive stress $\left(\sigma_{\max }\right)$ of each specimen is calculated according to Eq. (1).

$\sigma_{\max }=\frac{F_{\max }}{A}$

where $\mathrm{F}_{\max }$ is the maximum normal force applied perpendicular to the glass bundle's cross-sectional area A.

The critical force for buckling $\left(\mathrm{F}_{\mathrm{cr}}\right)$ for each column series is calculated based on Euler's formula. Tests carried out on the $A_{1}$ specimens (see Sect. 4.1) suggest that the selected adhesive allows the bundle to behave monolithically until a compressive load equivalent to at least $1000 \mathrm{kN}$. It is expected that the longer specimens, due to their high slenderness, will fail due to buckling at considerably lower force. Accordingly, the bundle can be assumed to be monolithic and the influence of the adhesive layer can be neglected for the determination of the critical buckling force $\left(\mathrm{F}_{\mathrm{cr}}\right)$ using Euler's buckling formula, seen in Eq. (2).

$F_{c r}=\frac{\pi^{2} E I}{(K L)^{2}}$

where, $\mathrm{E}$ is the modulus of Elasticity, I is the stiffness of the column about the axis it will buckle, typically the minor for asymmetric columns, $\mathrm{L}$ is the height of column and $\mathrm{K}$ is a factor accounting for the end conditions. In the case of both ends pinned, $\mathrm{K}$ is equal to 1.0 , whereas for both ends clamped it is 0.5 . Table 5 summa- 
Table 5 Material and geometry properties of the glass bundle

\begin{tabular}{lll}
\hline Property & Symbol & Value \\
\hline Glass modulus of elasticity & E & $64,000 \mathrm{~N} / \mathrm{mm}^{2}$ \\
Moment of inertia around minor axis & I & $64.3170 \mathrm{~mm}^{4}$ \\
Cross-sectional area of the bundle & A & $2552 \mathrm{~mm}^{2}$
\end{tabular}

rizes the parameters applied in the calculations, based on the material properties and geometry of the chosen glass profiles. The cross-sectional area and moment of inertia of the specimens are calculated based on the standard profile dimensions. The deviation in area due to manufacturing tolerances is considered of negligible influence to the ultimate stress and load values.

The slenderness ratio $(\lambda)$ of each specimen series has been calculated as the ratio of the effective length of the column to the least radius of gyration (r) of its cross section based on Eq. (3).

$\lambda=\frac{K L}{r}$,

Based on data regarding the slenderness ratio of several experimentally tested glass columns, Kamarudin et al. (2016) concludes that glass columns with a slenderness ratio $>40$ can be classified as slender and are expected to fail due to flexural buckling. Indeed, all three series of specimens failed by buckling at their middle zone, as was anticipated, since their slender proportions result in tensile forces arising from the buckling deformations and out of plane bending that typically prevail (O’ Regan 2014).

In the $\mathrm{B}_{1}$ series of prototypes initial cracking was observed in loads significantly lower than their maximum load-carrying capacity, which ranged between
130-199 MPa. In specific, specimen 2 cracked at $260 \mathrm{kN}$ and reached a maximum load of $389 \mathrm{kN}$; a load almost 1.5 times higher than the one causing the initial cracking. Specimen 3 initially cracked at $120 \mathrm{kN}$ and failed under a load more than 4 times as high $(508 \mathrm{kN})$. When reaching their maximum load all prototypes shattered suddenly in small pieces without maintaining any post-breakage carrying capacity. The load-displacement diagram of the three specimens of the $\mathrm{B}_{1}$ series is seen in Fig. 17.

Based on the Eq. (2) the expected buckling force for the $\mathrm{B}_{1}, 1500 \mathrm{~mm}$ long specimens assuming a clamped configuration was estimated to be $722 \mathrm{kN}$. This value exceeds considerably the maximum load the specimens could actually carry and cannot be solely attributed to induced eccentricities or flaws during the production of the specimens. A critical factor for the total carrying capacity are the end conditions of the specimen. Although the specimens were considered clamped in this series, each bundle was only kept in position by the pressure of the machine heads. Hence, it is possible that the large deviation between estimated and measured critical load is due to insufficient restrain at the clamped connections. It is probable that the aluminium caps started to twist during testing and functioned in between a pinned and a clamped connection. Indeed, if assuming connections are pinned, the specimens would be expected to start buckling at a significantly lower load of $177 \mathrm{kN}$. In these tests, the specimens failed between 330 and $508 \mathrm{kN}$, a range lying between clamped and pinned boundary conditions.

In the case of $\mathrm{B}_{2}$ and $\mathrm{C}_{1}$ specimens, where the pinned top and bottom connections were realized more accurately, all specimens failed close to the theoretical crit-
Fig. 17 Load-displacement diagram of the $B_{1}$ specimens

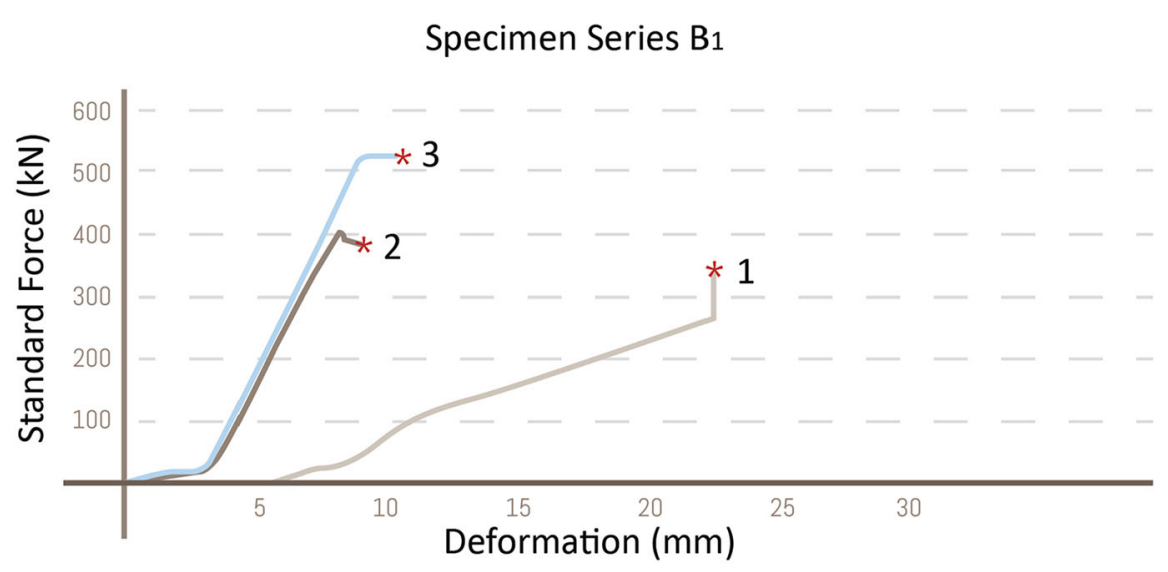




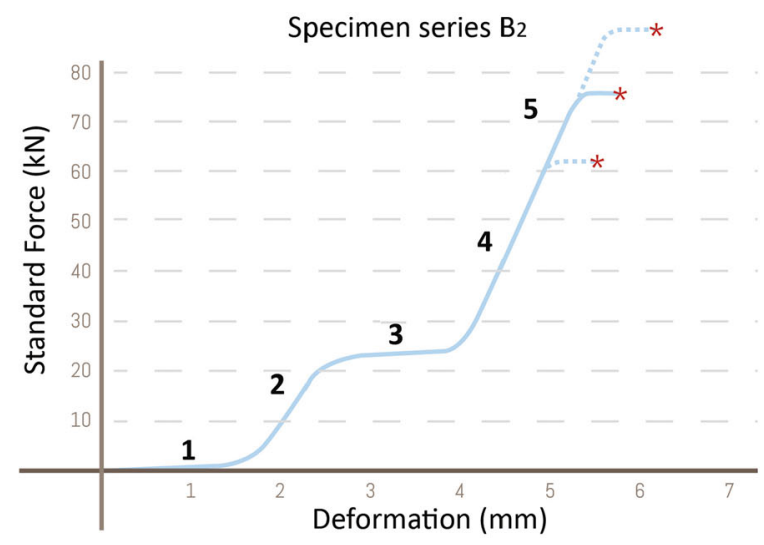

Fig. 18 Left Indicative load-displacement diagram of the $\mathrm{B}_{2}$ specimens. Only the data of one specimen (indicated by the continuous line) were accurately recorded by the compressing machine. The failure of the other two specimens (indicated by dotted lines) is indicated here based on the observations and

ical buckling force of $70.5 \mathrm{kN}$. The influence of the spliced joints and of eccentricities during fabrication seems to have only a minor influence on the obtained stresses. Specifically, the $\mathrm{B}_{2}$ specimens failed by buckling in a complete way in a load range between 63 and $90 \mathrm{kN}$ (see left diagram of Fig. 18). In two specimens, initial cracking was observed in a force approx. $20 \mathrm{kN}$ less than the failure load.

In comparison, the post-tensioned $\mathrm{C}_{1}$ specimens failed in a lower load range, yet with significantly narrower spread, between 62.7 and $69 \mathrm{kN}$ and visible buckling, as it can be seen on the right diagram of Fig. 18.

The consistency of the values and the relatively ductile failure mode can be attributed to the integration of the post-tensioned steel tendon. The post-tensioning seems to have successfully prevented initial crack propagation due to surface defects, resulting in more consistent results. Indeed, no significant cracking was observed in these specimens prior to failure. Also, it can be seen in Fig. 18 that the $C_{1}$ specimens demonstrate a relatively ductile behaviour and considerably greater deformations compared to the non-post-tensioned variant, providing warning prior to failure. When the column finally fails as a result of buckling, only the glass on one side of the column breaks away. The glass on the compressive side of the buckling failure is held in place by the post-tensioning tendon (see Fig. 19). The column also maintains a limited load-carrying capacity, attributed mainly to the tendon's tensile capabil-

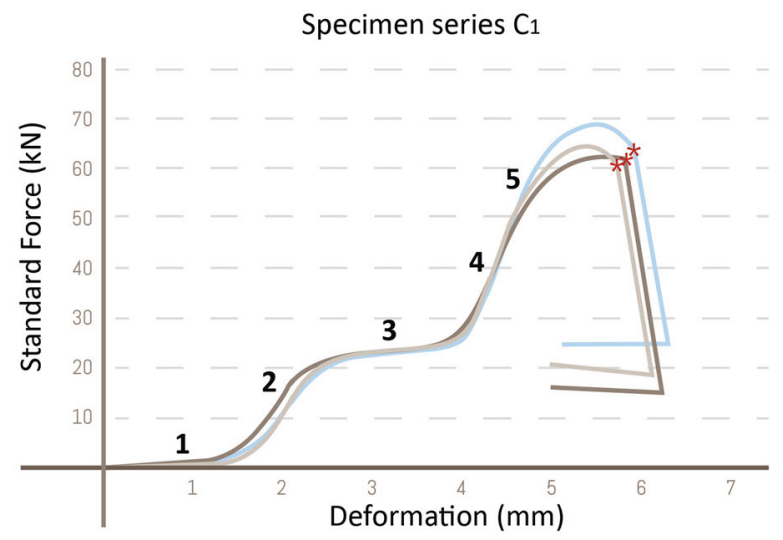

failure load recorded during testing. Right Load-displacement diagram of the $\mathrm{C}_{1}$ specimens with post-tensioning. In both diagrams: 1 setting of the machine, 2 column is slightly compressed, 3 area where the lead layer is compressed, 4 column is loaded in compression, 5 initiaton of buckling

ity. In general, the ability of the column to withstand complete failure (see Fig. 20) and the consistent failure values result in an increased structural reliability which allows reduction of the imposed safety factors that generally apply to such glass structural members.

In an ideal scenario, where the tendon and the glass would fully cooperate, the tendon would postpone initial buckling as it would prevent the glass from moving away from the neutral axis; as a result it should fail in a higher load compared to the non-post-tensioned variant. The latter did not occur due to insufficient cooperation between the glass bundle and the steel tendon because of the inevitable manufacturing tolerances of the rods. The American Concrete Institute (2004) states in ACI-318-5 building code regarding the application of pre-stress on structural members, that a structural member cannot buckle under pre-stress applied if the posttensioned tendon is in direct contact with the member or in sheathing not excessively larger than the tendon. Even though this code is generally applied to concrete members, the mechanical effect applies to structural members regardless of the material used. The tolerance of at least $1 \mathrm{~mm}$ between the tendon and the glass bundle in our case prevented the full-collaboration between the two elements. Instead, the glass was free to start moving away from the neutral axis of the column once the critical buckling force was reached. At that time, even though the tendon remained in the neutral axis, it was unable to prevent the initiation of buckling. 
Fig. 19 Left Failure pattern of a specimen of the $\mathrm{B}_{2}$ series. Right Failure pattern of a specimen of the $\mathrm{C}_{1}$ series
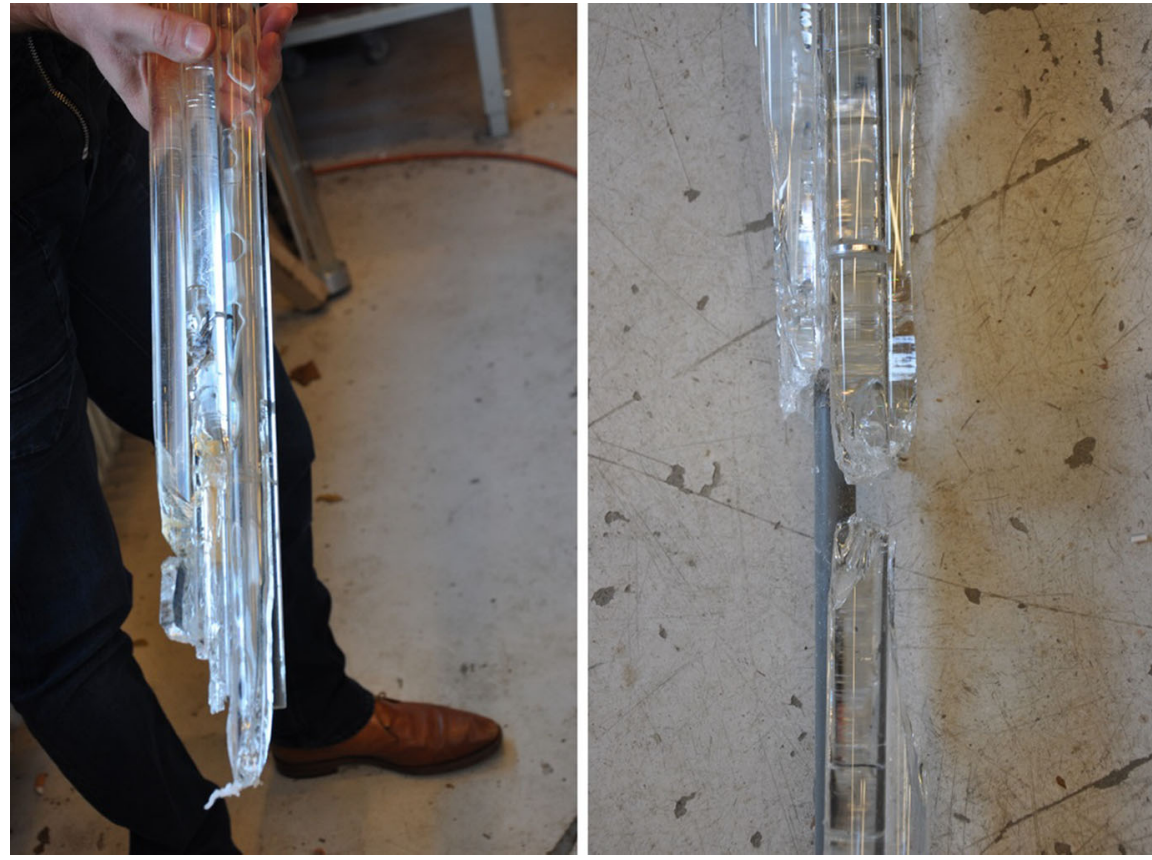

Fig. 20 Characteristic failure of a prototype from the $\mathrm{B}_{2}$ (left) and the $\mathrm{C}_{1}$ (right) series
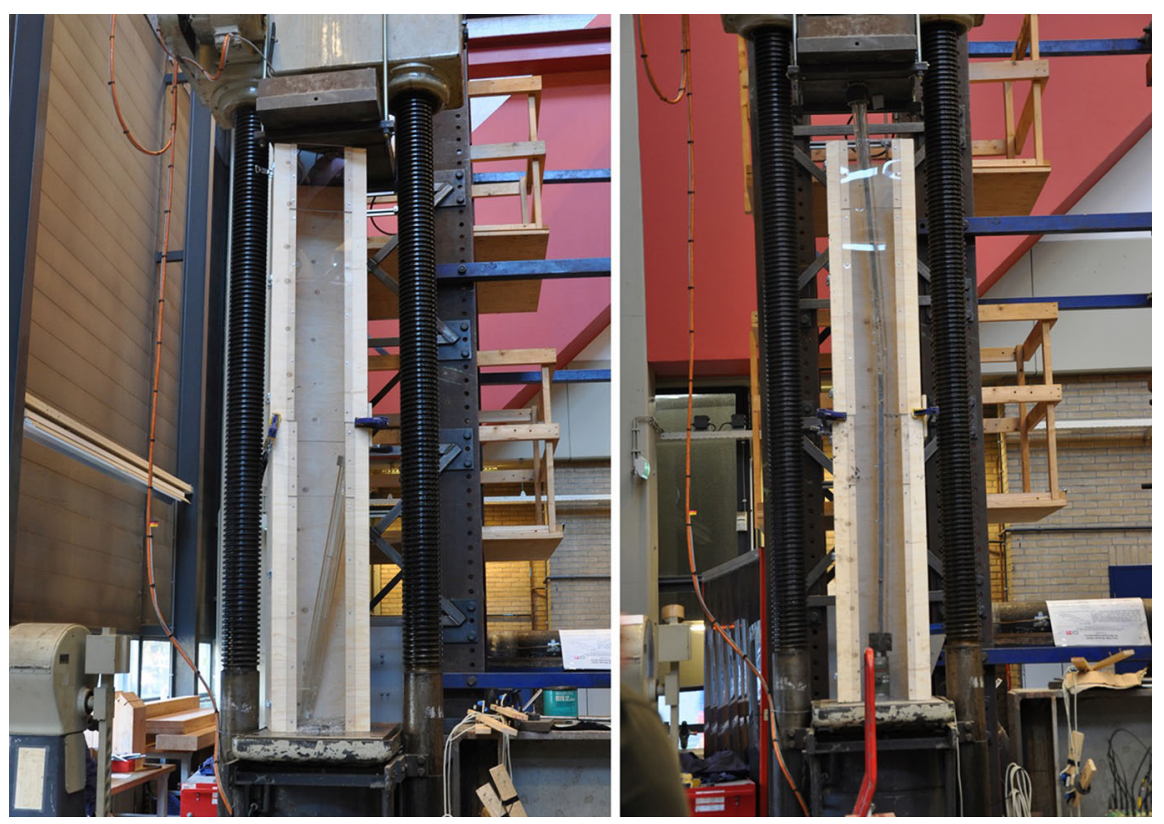

Therefore, due to this relevant movement, the pre-stress applied through the tendon seems to have contributed to the critical buckling force, resulting in a seemingly lower failure load. Indeed, it can be seen at Fig. 18 that buckling is already triggered at a load of approx. $45 \mathrm{kN}$. If this is the case, and the pre-stress contributes to the compressive force, the specimens actually resist an overall higher compressive load than that of the nonpost-tensioned variant. It is expected that optimizing the tendon configuration will result in higher failure loads as the tendon will then be in tight contact with the sheathing, constraining the lateral movement of the glass towards eccentricity. Since the manufacturing tolerances of the central glass profile cannot be improved, 
the application of a heat shrink plastic tube of sufficient stiffness prior to the assembly and post-tensioning on a tendon of the closest diameter to the glass profile hole can significantly contribute to the cooperation of the different components of the column. In this way, the overall tolerance between the glass and the plasticcoated tendon can be confined to a few decimals of a millimetre.

\section{Conclusions and discussion}

A completely transparent, bundled glass column has been developed and physically tested towards the evaluation of its feasibility. The results indicate that the bundled glass column can be an elegant solution of sufficient compressive strength in the search of a transparent, load-bearing component.

The experimental data from the compressive testing of small-scale specimens suggest that the described bundled column behaves monolithically under loading when the selected adhesive is applied. The consistent high failure stresses of these specimens indicate that the soft lead interlayer can eliminate the effect of induced imperfections in the contact surface as well.

The latter also highlights the importance of proper detailing of the column's top and bottom connections for the estimation of the corresponding ultimate stresses. The load-carrying capacity of the specimen series $\mathrm{B}_{2}$ and $\mathrm{C}_{1}$ using accurately designed pinned connections proved to be within close proximity of the expected theoretical critical buckling force, assuming a monolithic glass bundle. In comparison, the carrying capacity of the $\mathrm{B}_{1}$ specimens that were clamped to the machine only by friction resulted in a critical force corresponding to a column configuration between a clamped and pinned situation.

Fluctuations of the load, variability of the material properties, eccentricities caused during production and uncertainties regarding the analytical models all contribute to lowering the probability of flawless behaviour. Still, the effect of the spliced joints using aluminium discs seems to have little influence on the final results. The performance could be further enhanced by applying monolithic rods of the desired length, or by forming longer members by welding the borosilicate rods together. Experimental testing of welded borosilicate rods by Bos et al. (2008) suggests that the reliability of glass welds is comparable to that of the main material and that the presence of a weld does not influence the specimen's strength.

Apart from the $A_{1}$ and $A_{2}$ series that were restricted to lengths of max. $500 \mathrm{~mm}$, all other tested specimens failed by buckling. Specimens of the $\mathrm{B}_{2}$ and $\mathrm{C}_{1}$ series ( $2400 \mathrm{~mm}$ long) failed in load values close to the expected critical force by Euler's formula. The $\mathrm{C}_{1}$ specimens, where post-tensioning was applied, presented a more consistent failure and a narrow load spread. Yet, post-tensioning of the column requires a very precise fit of the tendon to the glass component to increase the carrying capacity of the specimens. Still, the consistent and visible buckling failure, as well as the improved postbreakage behaviour of the column can greatly reduce the imposed safety factors. In this direction, the steel tendon can also be designed and engineered to provide an alternative, built-in load path that can reduce the consequences of failure.

Further work will focus on the development of the top and bottom connections as well as on increasing the safety of the column. For this, the effect of posttensioning will be further explored and a series of experiments will be conducted to explore in detail the column's performance.

The presented glass column design will be first applied in the truss elements of a temporary pedestrian $14 \mathrm{~m}$ long bridge at the TU Delft campus.

Acknowledgements The authors gratefully acknowledge Kees Baardolf for his technical assistance and remarkable insight in the manufacturing of the prototypes, Dr. ir. Christian Louter for his valuable feedback and Fred Schilperoort for operating the hydraylic machines used to carry out the experiments. The authors also express their gratitude to Spyros Oikonomopoulos for his valuable engineering feedback.

\section{Compliance with ethical standards}

Conflicts of interest On behalf of all authors, the corresponding author states that there is no conflict of interest.

Open Access This article is distributed under the terms of the Creative Commons Attribution 4.0 International License (http://creativecommons.org/licenses/by/4.0/), which permits unrestricted use, distribution, and reproduction in any medium, provided you give appropriate credit to the original author(s) and the source, provide a link to the Creative Commons license, and indicate if changes were made.

\section{References}

Achenbach, J., Behling, S., Doenitz, F.: Konstruktive Elementen aus Glasrohrprofilen. Glas Archit. Tech. 5, 5-10 (2002) 
Achenbach, J., Jung, H.: Konstruktive Element aus Glasrohrprofilen in Tragstrukturen - Systementwicklung, Herstellung and Anwendung. In: GlasKon 2003, pp. 29-34. Messe Munchen GmbH, Munich (2003)

Aiello, S., Campione, G., Minafo, G., Scibilia, N.: Compressive behaviour of laminated structural glass members. Eng. Struct. 33, 3402-3408 (2011)

Akerboom, R.: Glass columns, exploring the potential of free standing glass columns assembled from stacked cast elements. MSc, TU Delft (2016)

American Concrete Institute: Building code requirements for structural concrete and commentary. In: ACI 318-05 \& ACI 318R-05. American Concrete Institute, US (2004)

Bos, F., Giezen, C., Veer, F.: Opportunities for the welding and hot-shaping of borosilicate glass tubes in building structural applications. In: Bos, F., Louter, C., Veer, F. (eds.) Challenging Glass, pp. 193-204. IOS Press, Delft (2008)

Campione, G., Rondello, V.: Effects of shape of transverse crosssection on the load carrying capacity of laminated glass columns. Constr. Build. Mater. 61, 349-359 (2014)

Corning Museum of Glass: The Glass Giant. http://www.cmog. org/article/glass-giant (2011)

Delo Industrial Adhesives: Technical Information. DeloPhotobond 4468. Delo Industrial Adhesives, Windach (2014)

Delo Industrial Adhesives: Delo Photobond 4494 Technische Information. Delo Industrial Adhesives, Windach (2016)

Doenitz, F., Jung, H., Behling, S., Achenbach, J.: Laminated glass tubes as structural elements in building industry. In: Glass Processing Days, pp. 275-278. Tampere (2003)

Felekou, E.: Glass Tower in high-rise buildings. MSc, TU Delft (2016)

Granta Design Limited: CES EduPack 2015. Granta Design Limited, Cambridge (2015)

Kalamar, R., Bedon, C., Eliasova, M.: Experimental investigation for the structural performance assessment of square hollow glass columns. Eng. Struct. 113(4), 1-15 (2016)

Kamarudin, M.K., Disney, P., Parke, G.A.R.: Structural performance of single and bundled glass columns. ARPN J. Eng. Appl. Sci. 11(3), 1593-1599 (2016)

Kroller-Muller Museum: Roni Horn: opposites of white. http:// krollermuller.nl/en/roni-hornopposites-of-white (2007)

Nieuwenhuijzen, E.J., Bos, F.P., Veer, F.A.: The Laminated Glass Column. In: Glass Processing Days, Tampere (2005)

Nijsse, R.: Glass in Structures: Elements, Concepts, Designs. Birkhauser, Germany (2003)

Nijsse, R., ten Brincke, E.H.J.: Glass columns. In: Louter, C., Bos, F., Belis, J., Lebet, J. (eds.) Challenging Glass 4 \& COST Action TU0905 Final Conference, Lausanne 2014, pp. 625-632. Taylor \& Francis Group, London (2014)
O'Regan, C.: Structural Use of Glass in Buildings Second Ed. The Institution of Structural Engineers, London (2014)

Oikonomopoulou, F., Bristogianni, T., Nijsse, R., Veer, F.A.: Innovative structural applications of adhesively bonded solid glass blocks. Glass Performance Days, pp. 256-261. Glass Performance Days, Tampere (2015a)

Oikonomopoulou, F., Bristogianni, T., Veer, F., Nijsse, R.: Developing the bundled glass column. In: Cruz, P.J.S. (ed.) Third International Conference on Structures and Architecture (ICSA 2016). CRC Press, Portugal (2016)

Oikonomopoulou, F., Bristogianni, T., Veer, F., Nijsse, R.: The construction of the Crystal Houses facade: challenges and innovations. Glass Struct. Eng. (2017). doi:10.1007/ s40940-017-0039-4

Oikonomopoulou, F., Veer, F.A., Nijsse, R., Baardolf, K.: A completely transparent, adhesively bonded soda-lime glass block masonry system. J. Facade Des. Eng. 2(3-4), 201-222 (2015b). doi:10.3233/fde-150021

Ouwerkerk, E.: Glass columns. MSc, TU Delft (2011)

Overend, M., Vassallo, C., Camillieri, K.: The design, assembly \& performance of glass columns. In: 9th International Conference on Automotive and Architectural Glass (Glass Processing Days), Tampere, Finland (2005)

Petersen, R.I., Bagger, A.: Structural use of glass: Cruciform columns and glass portals with bolted connections subjected to bending. In: Glass Processing Days, pp. 381-385. Tampere (2009)

Saint Gobain: Physical Properties. http://uk.saint-gobainglass. com/appcommportalchilddetails/713/442/711/378 (2016)

Schittich, C., Staib, G., Balkow, D., Schuler, M., Sobek, W.: Glass Construction Manual 2nd Revised and Expanded Edition Ed. Birkhauser, Basel (2007)

SCHOTT: DURAN, Tubing, Capillary and Rod of Borosilicate Glass 3.3. In: AG, S. (ed.). Germany (2012)

SCHOTT AG: CONTURAX Product overview. In: SCHOTT (ed.). SCHOTT AG, Germany (2013)

SCHOTT AG: SCHOTT Tubing: glass tubes, rods and profiles. http://www.schott.com/tubing/english/index.html? appid=ph (2017)

Shigley, J.E., Mitchell, L.: Mechanical Engineering Design, 4th edn. McGraw-Hill Book Co, New York (1993)

SMOOTH-ON: Crystal Clear Series: Clear Urethane Casting Resins. In: SMOOTH-ON (ed.). SMOOTH-ON, US (2016)

Van Heugten, R.: Load-bearing glass columns: the stacked column. Master Thesis, Eindhoven University of Technology (2013)

Veer, F., Pastunink, J.R.: Developing a Transparent Tubular Laminated Column. In: Glass Processing Days, pp. 277-280. Tampere (1999) 